\title{
Putting one foot in front of the other
}

Shawn Alexander Hallett, 25, from Boston, Massachusetts, is a 2nd year Doctor of Dental Surgery and PhD in Oral Health Sciences (DDS/PhD) student at the University of Michigan School of Dentistry. He also has a BS in Biochemistry and Molecular Biology. He balances his studies with training to run a sub-three-hour marathon.

I live in Ann Arbor, Michigan, and usually get up at 6:00 am. I eat cereal with fruit and a handful of nuts at home then I walk to work, which is a mile away. I arrive at 7:00 am and leave the laboratory between 6:30-7:30 pm Monday to Friday. On the weekends, I work half days.

As a first generation college student, I didn't have much guidance from my family when applying to university. My dentist was a mentor to me and provided significant guidance while I was thinking about career opportunities. In general, I am fascinated by the intricacy of dentistry and enjoy testing my fine motor skills. I appreciate the ability
At Michigan, the $\mathrm{DDS} / \mathrm{PhD}$ programme I am following takes seven years to complete. In the first three years, we focus on completing didactic dental and graduate coursework, identifying a dissertation mentor and project, advancing to candidacy, applying to and receiving training grants from the NIH and conducting research. Years four through seven you transition into the dental school where you begin your clinical training and eventually treat patients.

Oral Health Sciences is an umbrella programme consisting of scientific themes. I work in the Craniofacial, Skeletal Biology and Disease unit where I study the

\section{'I enjoy pushing my mind and body to try and exceed my limits. It's not often that I will say no to a new challenge if I feel that I can be passionate about it and give it my $100 \%$ effort.'}

to provide care to a patient and visualise the impact of your work just days later. Importantly, I am interested in the application of basic science research to better understand how oral health diseases and congenital anomalies of the skull and face arise.

In 2016 I received my Bachelors of Science in Biochemistry and Molecular Biology at the University of Massachusetts Amherst. Following my graduation in 2016, I spent two years working as a researcher in the Craniofacial Developmental Biology Laboratory at the Massachusetts General Hospital (MGH). At the MGH, I utilised CRISPR-Cas9 genome editing technology to recapitulate human craniofacial anomalies in the zebrafish model organism.

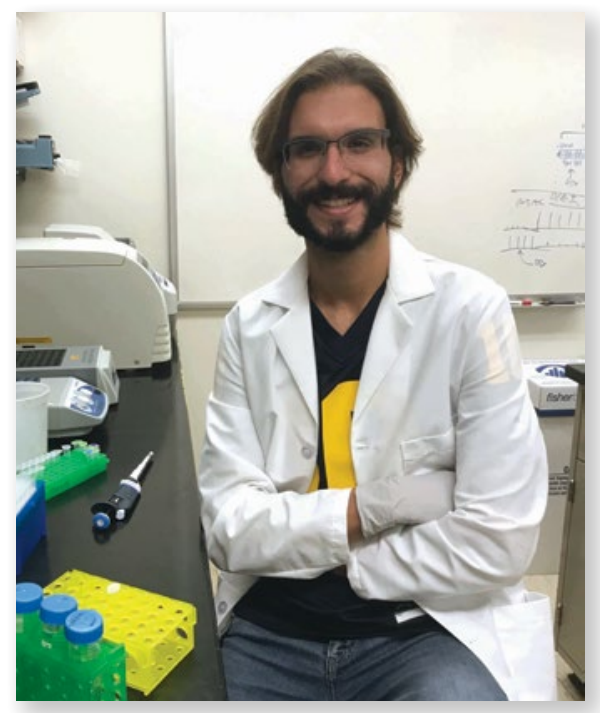

you make your daily schedule, you should always attempt to exceed that list.

I run between six to seven hours across five to six days weekly in the middle of a marathon training cycle. This amounts to 50-60 miles (80-96 km) each week.

I am very happy with my work-life balance. I know my limits and how to address my concerns should I become too stressed or if I am putting myself through too much training. Work-life balance is incredibly important to me and I believe its value extends so much further than one could imagine.

I don't really have a structured diet while I am training. However, I avoid eating highly processed foods, junk food, desserts and sugary drinks in general. I enjoy eating well-balanced meals incorporating a lean protein, lots of vegetables and a starch. This extends to meals that are eaten in restaurants. To be completely honest, on the nights after a morning long run I treat myself to a fast food meal because who doesn't enjoy Burger King from time to time? For lunch, I really enjoy bringing leftovers from the prior night's dinner. However, if I can attend a seminar with free lunch then I always try to be in attendance!

I also enjoy travelling and spending time with my partner, friends and family. When travelling, I separate myself from experiments, courses and programme requirements and try to relax and unwind. I am also a Michigan football season ticket holder (Go Blue!) and an avid New England Patriots fan. Lastly, I am a volunteer with Big Brothers Big Sisters [a US youth mentoring organisation] and greatly enjoy spending time with my 'little brother', inspiring him to pursue new and exciting opportunities throughout his life. 
4

I feel very satisfied after putting in a hard day's work. I know that I have become one step closer to achieving a goal, whatever it may be. I feel the same about marathon training. I enjoy pushing my mind and body to try and exceed my limits. It's not often that I will say no to a new challenge if I feel that I can be passionate about it and give it my $100 \%$ effort.

Although I am not actively seeing patients yet, once I reach that level of the programme I will be treating a diverse population of university students and individuals from the state of Michigan. I will be practising general dentistry; however, I can also assist in speciality clinics should I show an interest in doing so.

During the day, conducting experiments can be tedious so I enjoy listening to music and podcasts concurrently. At home, I love to cook and read for pleasure when I can. Above all the things I do to relax, running is at the top of my list. This is the one time of the day where I am alone with my thoughts without distractions. I don't think about school or work, I only focus on getting one foot in front of the other and I love that I am able to do that.
Dentistry is a fulfilling career that enables one to form meaningful relationships with patients that trust you and that can leave a lasting impact on a person's life. I hope that I can inspire young individuals to pursue opportunities in their lives that have interested them but seemed unattainable at the time and to form meaningful and lasting relationships with others. I never thought I would be where I am just a few years ago. Developing strong persistence and a curiosity and motivation to pursue my goals led me to where I am today. I owe my past, current and future successes to the individuals in my life who have supported me and provided me with excellent advice throughout my journey.

I arrive home between 7-7:30 pm. I'm currently in a long-distance relationship with my partner in Boston so we always make time to talk to one another and relax while watching of one of our favourite Netflix series. I go to sleep between 11-11:30 pm.

The three things I could not live without are curiosity, determination and of course, a pair of my trusted running shoes.

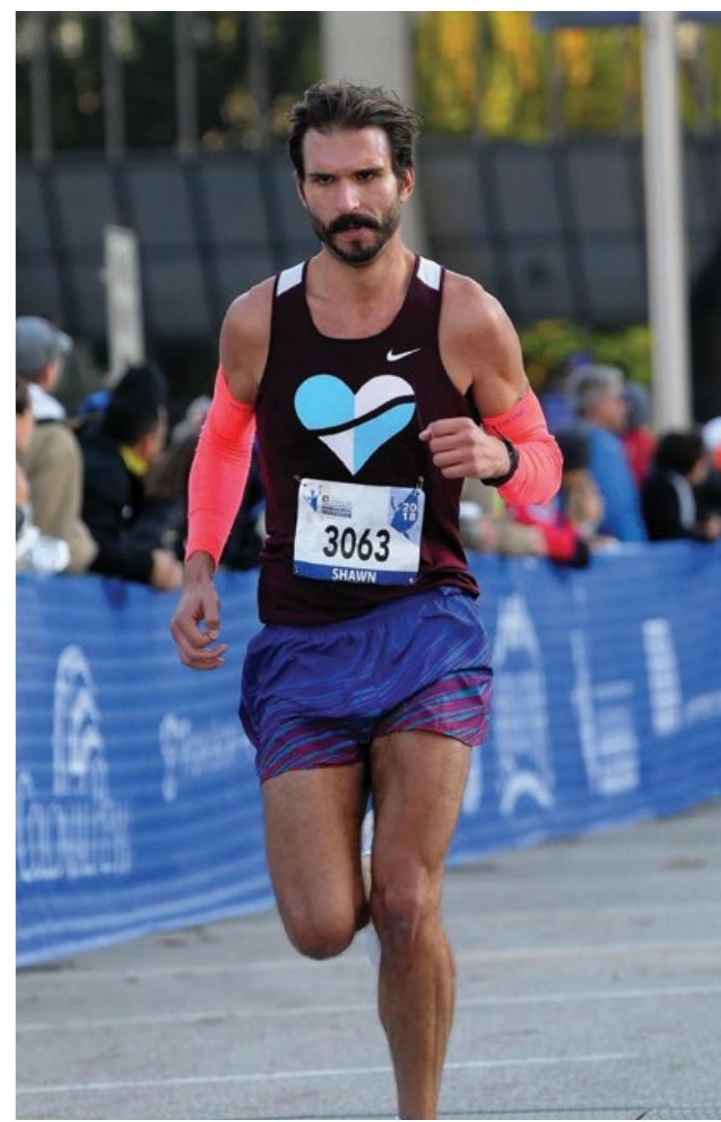

\section{Here has been an advertisement.}

\section{SPRINGERNATURE}

